\title{
Quantile-dependent expressivity of plasma adiponectin concentrations may explain its sex-specific heritability, gene- environment interactions, and genotype-specific response to postprandial lipemia
}

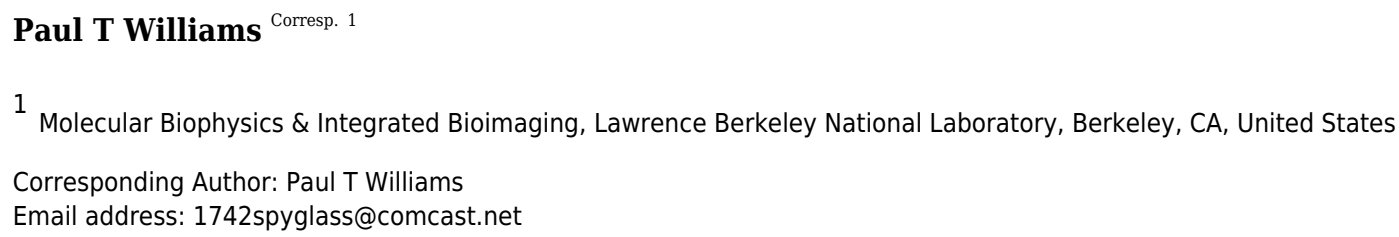

Background: "Quantile-dependent expressivity" occurs when the effect size of a genetic variant depends upon whether the phenotype (e.g. adiponectin) is high or low relative to its distribution. We have previously shown that the heritability $\left(h^{2}\right)$ of adiposity, lipoproteins, postprandial lipemia, pulmonary function, and coffee and alcohol consumption are quantile-specific. Whether adiponectin heritability is quantile specific remains to be determined. Methods Plasma adiponectin concentrations from 4182 offspring-parent pairs and 1662 sibships from the Framingham Heart Study were analyzed. Quantile-specific heritability from offspring-parent $\left(\beta_{\mathrm{OP}}, h^{2}=2 \beta_{\mathrm{oP}} /\left(1+r_{\text {spouse }}\right)\right)$ and full-sib regression slopes $\left(\beta_{\mathrm{FS}}, h^{2}=\left\{\left(1+8 r_{\text {spouse }} \beta_{\mathrm{FS}}\right)^{0.05}-1\right\} /\left(2 \mathrm{r}_{\text {spouse }}\right)\right)$ were robustly estimated by quantile regression with nonparametric significance assigned from 1000 bootstrap samples. Results: Quantile-specific $h^{2}( \pm \mathrm{SE})$ increased with increasing percentiles of the offspring's age- and sex-adjusted adiponectin distribution when estimated from $\beta_{\text {oP }}$ $\left(P_{\text {trend }}=2.2 \times 10^{-6}\right): 0.30 \pm 0.03$ at the $10^{\text {th }}, 0.33 \pm 0.04$ at the $25^{\text {th }}, 0.43 \pm 0.04$ at the $50^{\text {th }}$, $0.55 \pm 0.05$ at the $75^{\text {th }}$, and $0.57 \pm 0.08$ at the $90^{\text {th }}$ percentile, and when estimated from $\beta_{\mathrm{FS}}$ $\left(P_{\text {trend }}=7.6 \times 10^{-7}\right): 0.42 \pm 0.03$ at the $10^{\text {th }}, 0.44 \pm 0.04$ at the $25^{\text {th }}, 0.56 \pm 0.05$ at the $50^{\text {th }}$, $0.73 \pm 0.08$ at the $75^{\text {th }}$, and $0.79 \pm 0.11$ at the $90^{\text {th }}$ percentile. Consistent with quantiledependent expressivity, adiponectin's: 1) heritability was greater in women in accordance with their higher adiponection concentrations; 2) relationships to ADIPOQ polymorphisms were modified by adiposity in accordance with its adiponectin-lowering effect; 3 ) response to rosiglitazone was predicted by the $45 T>G$ ADIPOQ polymorphism; 4) difference by $A D I P O Q$ haplotypes increased linearly with increasing postprandial adiponectin 
concentrations. Conclusion: Adiponectin heritability is quantile dependent, which may explain sex-specific heritability, gene-environment and gene-drug interactions, and postprandial response by haplotypes. 
1 Quantile-dependent expressivity of plasma adiponectin concentrations may explain its sex-

2 specific heritability, gene-environment interactions, and genotype-specific response to

3 postprandial lipemia.

4

5 Paul T Williams, PhD

6 Lawrence Berkeley National Laboratory

7 Molecular Biophysics \& Integrated Bioimaging Division

81 Cyclotron Road

9 Berkeley, CA 94720

10

11 Running title: Quantile-specific adiponectin heritability

12

13

14 Complete address of corresponding author and to whom correspondence should be addressed:

15

16 Paul T Williams

17 Lawrence Berkeley National Laboratory

18 Molecular Biophysics \& Integrated Bioimaging

191 Cyclotron Road

20 Berkeley, CA 94720

21 Email. ptwilliams@,lbl.gov

22

23 
Abstract

27

28 Background: "Quantile-dependent expressivity" occurs when the effect size of a genetic variant 29 depends upon whether the phenotype (e.g. adiponectin) is high or low relative to its distribution.

30 We have previously shown that the heritability $\left(h^{2}\right)$ of adiposity, lipoproteins, postprandial 31 lipemia, pulmonary function, and coffee and alcohol consumption are quantile-specific. Whether 32 adiponectin heritability is quantile specific remains to be determined.

33 Methods Plasma adiponectin concentrations from 4182 offspring-parent pairs and 1662 sibships 34 from the Framingham Heart Study were analyzed. Quantile-specific heritability from offspring35 parent $\left(\beta_{\mathrm{OP}}, h^{2}=2 \beta_{\mathrm{OP}} /\left(1+\mathrm{r}_{\text {spouse }}\right)\right)$ and full-sib regression slopes $\left(\beta_{\mathrm{FS}}, h^{2}=\left\{\left(1+8 \mathrm{r}_{\mathrm{spouse}} \beta_{\mathrm{FS}}\right)^{0.05}\right.\right.$ -

$\left.361\} /\left(2 r_{\text {spouse }}\right)\right)$ were robustly estimated by quantile regression with nonparametric significance 37 assigned from 1000 bootstrap samples.

38 Results: Quantile-specific $h^{2}( \pm \mathrm{SE})$ increased with increasing percentiles of the offspring's age39 and sex-adjusted adiponectin distribution when estimated from $\beta_{\mathrm{OP}}\left(\mathrm{P}_{\text {trend }}=2.2 \times 10^{-6}\right): 0.30 \pm 0.03$ at the $10^{\text {th }}, 0.33 \pm 0.04$ at the $25^{\text {th }}, 0.43 \pm 0.04$ at the $50^{\text {th }}, 0.55 \pm 0.05$ at the $75^{\text {th }}$, and $0.57 \pm 0.08$ at the $90^{\text {th }}$ percentile, and when estimated from $\beta_{\mathrm{FS}}\left(\mathrm{P}_{\text {trend }}=7.6 \times 10^{-7}\right): 0.42 \pm 0.03$ at the $10^{\text {th }}, 0.44 \pm 0.04$ at 42 the $25^{\text {th }}, 0.56 \pm 0.05$ at the $50^{\text {th }}, 0.73 \pm 0.08$ at the $75^{\text {th }}$, and $0.79 \pm 0.11$ at the $90^{\text {th }}$ percentile.

43 Consistent with quantile-dependent expressivity, adiponectin's: 1) heritability was greater in 44 women in accordance with their higher adiponection concentrations; 2) relationships to $A D I P O Q$ 45 polymorphisms were modified by adiposity in accordance with its adiponectin-lowering effect; 46 3) response to rosiglitazone was predicted by the $45 \mathrm{~T}>\mathrm{G} A D I P O Q$ polymorphism; 4) difference 47 by $A D I P O Q$ haplotypes increased linearly with increasing postprandial adiponectin 48 concentrations.

49 Conclusion: Adiponectin heritability is quantile dependent, which may explain sex-specific 50 heritability, gene-environment and gene-drug interactions, and postprandial response by 51 haplotypes. 
53

54

55

Abbreviation key

56

57 ADIPOQ Adiponectin, C1Q And Collagen Domain Containing

58 APOA5 Apolipoprotein A5 gene

$59 \quad \beta_{\mathrm{FS}} \quad$ Full-sib regression slope

$60 \beta_{\mathrm{OM}}$

Offspring mid-parental regression slope

$61 \beta_{\mathrm{OP}}$

Offspring-parent regression slope

62 BMI

Body mass index

63 ELISA

Enzyme-linked immunosorbent assay

64 GWAS Genome-wide association studies

$65 h^{2}$

Heritability in the narrow sense

66 NHLBI National Heart Lung and Blood Institute

67 Q-Q plot Quantile-quantile plot

68 SD

Standard deviation

69 SE

Standard error

70 SNP

Single nucleotide polymorphism

71 T2DM

Type 2 diabetes mellitus

72

73 
77 Adiponectin is a $30 \mathrm{kDa}$ circulating adipocyte-derived protein that is a potent insulin sensitizer

78 that regulates energy homeostasis and glucose tolerance in muscle and liver [1]. Low adiponectin

79 concentrations are associated with insulin resistance, type 2 diabetes mellitus (T2DM), coronary

80 artery disease, lipodystrophy, nonalcoholic hepatic steatosis, and essential hypertension, and they

81 precede the development of insulin resistance and myocardial infarction [1]. Meta-analysis

82 showed that low plasma adiponectin concentrations predicted increased T2DM risk in 14,598

83 subjects from 13 prospective studies [2]. Paradoxically, prospective studies also find that high

84 adiponectin concentrations is a risk factor for all-cause and cardiovascular mortality [3]. 85

86 Twenty published estimates of adiponectin heritability show its plasma concentrations to be

87 highly heritable (i.e., $h^{2}=0.39$ [4,5], 0.42 [6,7], 0.47 [8] 0.48 [9,10], 0.55 [11,12], 0.58 [13], 0.62

88 [14], 0.64 [15], 0.67 [16], 0.68 [16], 0.70 [9,17], 0.71 [15], 0.79 [13], 0.88 [18], 0.93 [19]). None

89 report any difference in heritability between sexes. All but two studies [6,7] used adiponectin 90 concentrations that were logarithmically $[4,5,9-15,17-19]$ or cube-root transformed $[8,16]$. The

91 variation in heritability estimates across reports is likely the result of small sample size, different

92 statistical methodologies, differences between twin- and pedigree-based estimates, and

93 population heterogeneity.

94

95 "Quantile-dependent expressivity" is said to occur when the phenotypic expression of a gene 96 depends upon the percentile of the phenotype, i.e., whether the trait (e.g., adiponectin) is high or 97 low relative to its distribution [20]. This is in contrast to the traditional estimate of a genetic 98 effect size that is assumed to be constant across all population percentiles. Quantile-dependent 99 expressivity has been demonstrated for adiposity [20,21], lipoproteins [20,22,23], pulmonary 100 function [24], coffee intake [25], and alcohol intake [26]. Moreover, the genetic effect sizes of 101 single nucleotide polymorphisms (SNPs) affecting triglycerides have been shown to increase and 102 decrease within individuals in accordance with increasing and decreasing postprandial 103 triglyceride concentrations, consistent with quantile-dependent expressivity [27]. 
105 An important consequence of quantile-dependent expressivity is that the selection of subjects for

106 characteristics that distinguish high vs. low phenotypes can yield different genetic effects

$107[20,22]$. Adiponectin concentrations are greater in women than men [5-10,12,15-18,28], increase

108 with rosiglitazone treatment [29], increase during postprandial lipemia [30], and decrease with

109 adiposity [31-38]. It remains to be determined whether the heritability of adiponectin

110 concentrations is quantile-dependent, and whether this produces significant heritability

111 differences by sex, genotype-specific increases during rosiglitazone treatment or postprandial

112 lipemia, and gene-environment interactions by adiposity level.

113

114 We therefore used nonparametric quantile regression $[39,40]$ to test whether untransformed

115 adiponectin concentrations exhibit quantile-dependent heritability in the narrow-sense $\left(h^{2}\right)$ as

116 estimated from offspring-parent $\left(\beta_{\mathrm{OP}}\right)$ and full-sib $\left(\beta_{\mathrm{FS}}\right)$ regression slopes [41] in a large

117 population (Framingham Heart Study [42-44]). Untransformed concentrations were used because

118 quantile regression does not require normality, and no biological justification has been give for

119 its logarithmic transformation. Heritability was studied because between $5 \%$ and $9 \%$ of the

120 variation in adiponectin is accounted for by variants within the gene encoding adiponectin

121 (ADIPOQ) and other loci [45,46]. However, because heritability lacks the specificity of directly

122 measured genotypes, we also examined published studies that measured genetic variants directly

123 from the perspective of quantile-dependent expressivity to establish external validity and

124 generalizability.

125

126

Methods

127

128

129 The data were obtained from the National Institutes of Health FRAMCOHORT, GEN3,

130 FRAMOFFSPRING Research Materials obtained from the National Heart Lung and Blood

131 Institute (NHLBI) Biologic Specimen and Data Repository Information Coordinating Center.

132 The Original Framingham cohort consisted of men and women between the ages of 30 and 62

133 from the town of Framingham, Massachusetts [42]. The Offspring (generation 2) Cohort

134 consisted of 5,124 adult children of the original participants and their spouses who were first

135 examined between 1971 and 1975, re-examined eight years later, and then every three to four 
136 years thereafter [43]. Children of the Offspring Cohort were recruited to form the Third

137 Generation Cohort [44]. Subjects were at least 16 years of age and not self-identified as

138 nonwhite or Hispanic. Adiponectin concentrations were measured on stored blood samples

139 frozen at $-80^{\circ} \mathrm{C}$ from examination 7 of the Framingham Offspring Cohort and examination 1 of

140 the Framingham Third Generation Cohort by ELISA (R\&D Systems) with an average interassay

141 coefficients of variation $<5 \%$ [47]. The statistical analyses were approved by Lawrence Berkeley

142 National Laboratory Human Subjects Committee (HSC) for protocol "Gene-environment

143 interaction vs. quantile-dependent penetrance of established SNPs (107H021)" LBNL holds

144 Office of Human Research Protections Federal wide Assurance number FWA 00006253.

145 Approval number: 107H021-13MR20. The original surveys were conducted under the direction

146 of the Framingham Heart Study human use committee guidelines, with signed informed consent

147 from all participants or parent and/or legal guardian if $<18$ years of age.

148

149 Statistics Age and sex adjustment was performed separately for each examination of the

150 Offspring and Third Generation Cohorts using standard least-squares regression with the

151 following independent variables: female $(0,1)$, age, age ${ }^{2}$, female $\mathrm{x}$ age, and female $\mathrm{x}$ age ${ }^{2}$.

152 Individual subject values were taken as the average of the residuals over all available

153 examinations. Offspring-parent correlations and regression slopes were computed by assigning a

154 weight of one-half to the child-father and one-half to the child-mother pair (if both parents

155 available), and assigning a weight of one to the child-parent pair if only one parent was available.

156 Offspring-midparental correlations and regression slopes were computed by comparing each

157 child's age and sex-adjusted value to the average of the age and sex-adjusted parental values in

158 those families having both parents. Full-sibling correlations were obtained by constructing all

159 possible pairs using double entry [48]. Unadjusted quantile regression analysis means an

160 unadjusted dependent variable (e.g., offspring, sib) was compared to the age and sex-adjusted

161 independent variables (i.e., parent, other sibs). The number of degrees of freedom for the

162 standard error was adjusted to $\Sigma \mathrm{k}_{\mathrm{i}}-2$ for offspring-parent and midparental regression slopes and

163 correlations, and $\Sigma\left(\mathrm{k}_{\mathrm{i}}-1\right)$ for sibship correlations and regression slopes, where $\mathrm{k}_{\mathrm{i}}$ is the number of

164 offspring in family $\mathrm{i}$ and the summation is taken over all $\mathrm{i}, \mathrm{i}=1, \ldots, \mathrm{N}$ nuclear families [48].

165 Slopes are presented \pm SE.

166 
167 Simultaneous quantile regression is a well-developed statistical procedure [39] that estimates the

168 regression coefficients for multiple quantiles using linear programming to minimize the sum of

169 asymmetrically weighted absolute residuals, and bootstrap resampling to estimate their

170 corresponding variances and covariances [40]. Simultaneous quantile regression was performed

171 using the "sqreg" command of Stata (version. 11, StataCorp, College Station, TX) with one

172 thousand bootstrap samples drawn to estimate the variance-covariance matrix for the 91 quantile

173 regression coefficients between the $5^{\text {th }}$ and $95^{\text {th }}$ percentiles, and the post-estimation procedures

174 (test and lincom) to test linear combinations of the slopes after estimation with $\Sigma \mathrm{k}_{\mathrm{i}}-2$ degrees of

175 freedom for offspring-parent regression slopes and $\Sigma\left(\mathrm{k}_{\mathrm{i}}-1\right)$ degrees of freedom for sibship

176 regression slopes. Quantile-specific expressivity was assessed by: 1) estimating quantile-specific

$177 \beta$-coefficient for the $5^{\text {th }}, 6^{\text {th }}, 95^{\text {th }}$ percentiles of the sample distribution using simultaneous

178 quantile regression (Figure 1, the $<5^{\text {th }}$ and $>95^{\text {th }}$ percentiles ignored because they were thought to

179 be less stable); 2) plotting the quantile-specific $\beta$ coefficients vs. the percentile of the trait

180 distribution; and 3) testing whether the resulting graph is constant, or changes as a linear,

181 quadratic, or cubic function of the percentile of the trait distribution using orthogonal

182 polynomials [49]. Heritability in the narrow sense $\left(h^{2}\right)$ was estimated as $h^{2}=2 \beta_{\mathrm{OP}} /\left(1+\mathrm{r}_{\text {spouse }}\right)$ from

183 offspring-parent regression slopes $\left(\beta_{\mathrm{OP}}\right), h^{2}=\beta_{\mathrm{OM}}$ from the offspring midparental slope $\left(\beta_{\mathrm{OM}}\right)$, and

$184 h^{2}=\left\{\left(1+8 \mathrm{r}_{\text {spouse }} \beta_{\mathrm{FS}}\right)^{0.5}-1\right\} / 2 \mathrm{r}_{\text {spouse }}$ from full-sibs regression slopes $\left(\beta_{\mathrm{FS}}\right)$ where $\mathrm{r}_{\text {spouse }}$ is the spouse

185 correlation [41]. "Quantile-specific heritability" refers to the heritability statistic $\left(h^{2}\right)$, whereas

186 "quantile-dependent expressivity" is the biological phenomenon of the trait expression being

187 quantile-dependent.

188

189 When $\beta_{\mathrm{OP}}$ for male and female offspring are included on the same graph, their quantile190 specific functions compares their heritabilities at the corresponding percentiles of their separate

191 distribution (e.g., the slope at the $50^{\text {th }}$ percentile of the daughters' distribution vs. the slope at the $19250^{\text {th }}$ percentile of the sons' distribution). However, the adiponectin concentration at the $50^{\text {th }}$

193 percentile of the daughters' distribution will be greater then the $50^{\text {th }}$ percentile of the sons'

194 distribution. Quantile-specific expressivity postulates that the genetic effects depend upon the

195 adiponectin concentration. Therefore, additional displays were created using Q-Q plots [50] to

196 re-plot the sons' and daughters' heritability at the same adiponectin concentrations. 
The results from other studies were re-interpreted from the perspective of quantile-dependent

199 expressivity using genotype-specific mean adiponectin concentrations presented in the original articles or by extracting these values from graphs using the Microsoft Powerpoint formatting palette (version 12.3.6 for Macintosh computers, Microsoft corporation, Redmond WA) as previously described [27].

203

204

Data availability: The data are not being published in accordance with the data use agreement between the NIH National Heart Lung, and Blood Institute and Lawrence Berkeley National Laboratory. However, the data that support the findings of this study are available from NIH National Heart Lung, and Blood Institute Biologic Specimen and Data Repository Information Coordinating Center directly through the website https://biolincc.nhlbi.nih.gov/my/submitted/request/ [51]. Restrictions apply to the availability of these data, which were used under license for this study. Those wishing a copy of the data set should contact the Blood Institute Biologic Specimen and Data Repository Information Coordinating Center at the above website, where they can find information on human use approval and data use agreement requiring signature by an official with signing authority for their institute. The public summary-level phenotype data may be browsed at the dbGaP study

Traditional estimates of familial concordance and heritability The sample characteristics

221 displayed in Table 1 show average adiponectin were significantly higher in women than men.

222 BMI was correlated with adiponectin concentrations $(\mathrm{r}=-0.31)$ when age and sex adjusted.

223 Spouse correlation for adjusted adiponectin concentrations was weak $\left(\mathrm{r}_{\text {spouse }}=0.04\right)$. The

224 offspring-parent regression slope for adjusted adiponectin concentrations $\left(\beta_{\mathrm{OP}} \pm \mathrm{SE}: 0.22 \pm 0.01\right)$,

225 computed from 1718 offspring with one parent and 1232 offspring with two parents, corresponds

226 to a heritability $\left(h^{2}\right)$ of $0.43 \pm 0.03$, the same as when estimated from $\beta_{\mathrm{OM}}\left(\beta_{\mathrm{OM}}=0.43 \pm 0.03\right)$.

227 There were 4587 full-sibs in 1662 sibships with age and sex-adjusted adiponectin concentrations, 
228 whose full-sib regression slope $\left(\beta_{\mathrm{FS}}\right)$ was $0.29 \pm 0.02$, which from Falconer's formula,

229 corresponds to a heritability of $h^{2}=0.57 \pm 0.04$.

230

231 Quantile-dependent expressivity. The $\beta_{\mathrm{OP}}$ 's (offspring-parent regression slopes) at the $10^{\text {th }}, 25^{\text {th }}$, $23250^{\text {th }}, 75^{\text {th }}$, and $90^{\text {th }}$ percentiles of the offspring's adiponectin distribution are presented in Figure $2331 \mathrm{~A}$, along with their corresponding heritability estimates $\left(h^{2}=2 * \beta_{\mathrm{OP}} /\left(1+\mathrm{r}_{\mathrm{spouse}}\right)\right)$. The slopes get

234 progressively greater with increasing percentiles of the adiponectin distribution. The heritability 235 at the $90^{\text {th }}$ percentile was 0.57 , which is $89.6 \%$ greater than the heritability at the $10^{\text {th }}$ percentile

$236\left(\mathrm{P}_{\text {difference }}=0.001\right)$. The quantile-specific heritability plot of Figure 1B presents these slopes, along 237 with those of the other percentiles between the $5^{\text {th }}$ and $95^{\text {th }}$ percentiles. They show heritability 238 increased linearly (i.e., slope \pm SE: $0.0038 \pm 0.0008, \mathrm{P}_{\text {linear }}=2.2 \times 10^{-6}$ ) with increasing percentiles of 239 the offspring's distribution. There was no significant evidence of nonlinearity (i.e.,

$\left.240 \mathrm{P}_{\text {quadratic }}=0.84 ; \mathrm{P}_{\text {cubic }}=0.06\right)$. Quantile-specific heritability was individually significant $\left(\mathrm{P} \leq 7.2 \times 10^{-}\right.$

$241^{7}$ ) for all percentiles of the offspring's distribution. If the heritability over all quantiles was

242 constant, then the line segments would all be parallel in Figure 1A, and Figure 1B would show a 243 flat line having zero slope. Figure 1C displays the quantile regression analysis for $h^{2}$ estimated 244 from full-sib regression slopes $\left(\beta_{\mathrm{FS}}\right)$. Each one-percent increase in the adiponectin distribution 245 was associated with a $0.0052 \pm 0.001$ increase in heritability and a $0.0026 \pm 0.0005$ increase in the 246 full-sib regression slope $\left(\mathrm{P}_{\text {linear }}=7.6 \times 10^{-7}\right)$.

248 Significant quantile-dependent expressivity was replicated when 506 sibships from the Offspring 249 Cohort and 1156 sibships from the Third Generation Cohorts were analyzed separately, i.e., $\beta_{\mathrm{FS}}$ 250 increased $0.0023 \pm 0.0011$ in the Offspring Cohort $(\mathrm{P}=0.04)$ and $0.0028 \pm 0.0006$ in the Third 251 Generation Cohort $\left(\mathrm{P}=8.0 \times 10^{-6}\right)$ for each one-percent increment in the sibs' adjusted adiponectin 252 concentrations.

253

254 Male-female differences in heritability. The preceding analyses showed that adiponectin 255 heritability increased with increasing percentiles of the offspring distribution for the combined 256 sample of male and female age- and sex-adjusted offspring. Figure 2 however, shows that the 257 female adiponectin distribution is shifted towards to the right of the males. Correspondingly, the 258 analyses of Figure 1B suggest that female heritability should be greater than that of the males. In 
259 fact, heritability as classically estimated by standard regression was higher in females than males

260 for adiponectin $\left(0.53 \pm 0.05\right.$ vs. $\left.0.33 \pm 0.03, \mathrm{P}<10^{-15}\right)$ and Figure $3 \mathrm{~A}$ shows that the quantile-

261 specific heritability was higher in females than males at each percentile of their respective

262 distribution. Adiponectin heritability was significantly greater in females than males $(\mathrm{P}<0.05)$ for

263 each percentile between the $8^{\text {th }}$ and the $77^{\text {th }}$ percentile.

264

265 From the perspective of quantile-dependent expressivity, the problem with Figure 3A is that 266 comparing male and female heritability at their $10^{\text {th }}$ percentiles means comparing the male

267 heritability at an unadjusted adiponectin concentration of $2.25 \mu \mathrm{g} / \mathrm{ml}$ with the female heritability 268 at an unadjusted concentration $4.25 \mu \mathrm{g} / \mathrm{ml}$, comparing their heritability at their $50^{\text {th }}$ percentile 269 means comparing the male heritability at $5.18 \mu \mathrm{g} / \mathrm{ml}$ with the female heritability at $9.98 \mu \mathrm{g} / \mathrm{ml}$, 270 and comparing their heritability at the $90^{\text {th }}$ percentiles means comparing the male heritability at

$27111.41 \mu \mathrm{g} / \mathrm{ml}$ with the female heritability at $18.91 \mu \mathrm{g} / \mathrm{ml}$. Specifically, quantile-dependent

272 expressivity predicts an increase in heritability with increasing adiponectin concentrations.

273 Therefore the male and female heritability graphs were re-plotted to the same adiponectin 274 concentrations in Figure 3B using quantile-quantile (Q-Q) plots (see methods). This eliminated 275 the significant differences between the male and female heritability plots. Similarly, Figure 4A 276 and 4B and presents the analyses for the full-sib estimates of heritability showing substantial 277 differences between the male and female graphs when matched by the percentiles of their 278 corresponding age and sex-adjusted distribution that are eliminated when matched by their 279 corresponding unadjusted adiponectin concentrations. Figures $3 \mathrm{C}$ and $4 \mathrm{C}$ shows that a simple 280 plot of the unadjusted quantile regression slopes by percentiles of the offspring or sib distribution 281 includes the re-plotted male and females graphs of figures $3 \mathrm{~B}$ and $4 \mathrm{~B}$ within its $95 \%$ confidence 282 interval.

283

\section{Discussion}

285

286 Our analyses suggest that plasma adiponectin concentrations exhibit quantile-dependent expressivity. The finding was replicated using the full-sib regression analyses in the Framingham Offspring Cohort $\left(\mathrm{P}_{\text {linear }}=0.04\right)$ and the Framingham Third Generation Cohort separately $\left(\mathrm{P}_{\text {linear }}=8.0 \times 10^{-6}\right)$. Moreover, the stronger adiponectin heritability in female than male 
290 offspring can be largely attributed to quantile-dependent expressivity and the females' higher

291 concentrations (Figures 3 and 4). A similar analytic approach was previously used to show that

292 quantile-dependent expressivity explained the larger male than female postprandial triglyceride

293 difference for the APOA5 -1131 T>C polymorphism [27]. These examples suggest pro forma

294 statistical adjustment for sex may conceal important properties of a trait's heritability. In fact, the

295 replotted heritability of Figures 3C and 4C show the unadjusted offspring adiponectin

296 concentrations provided the simplest representation of their quantile-specific heritabilities.

297

298 Women have higher adiponectin concentrations due at least in part to the adiponection-lowering

299 effects of testosterone [28]. Whereas sex-differences in adiponectin concentrations are

300 consistently reported [5-10,12,15-18], sex-differences in their heritabilities are not. This we

301 attribute to their reliance on statistical procedures that require normally distributed data and

302 logarithmic or other data transformations. These transformations accentuate the slope at lower

303 phenotype values and diminish the slope at higher values. For example, using the Framingham

304 data reported here, the traditional (nonquantile) offspring-parent slope $\left(\beta_{\mathrm{OP}} \pm \mathrm{SE}\right)$ for female vs.

305 male offspring was $0.2733 \pm 0.0238$ vs. $0.1697 \pm 0.0171\left(\mathrm{P}_{\text {difference }}<10^{-15}\right)$ for the untransformed

306 data and $0.3221 \pm 0.0248$ vs. $0.3255 \pm 0.0294$ for the log-transformed data $\left(\mathrm{P}_{\text {difference }}=0.93\right)$. The

307 important point is that quantile regression and its bootstrap-derived standard errors do not require

308 a normal distribution $[39,40]$. There is no biological imperative to logarithmically or otherwise

309 transform the data. That is not to say that quantile-regression is invariant to data transformations,

310 which they are not (Supplementary Figure 1), but rather the rationale for transformations should

311 ideally be biologically based, not statistically based, and its consequences acknowledged.

312

313 All the major genomewide association studies were performed on logarithmic [53-56] or z-score

314 transformed adiponectin concentrations [57]. Our results suggest this statistical accommodation

315 may work against the goal of identifying SNPs affecting adiponectin concentrations.

316 Specifically, Figure 1 suggests that the transformation accentuates the genetic effect at low

317 concentrations (where the genetic effects are weakest) and diminishes the genetic effect at higher

318 values concentrations (where the genetic effects are strongest). Our previous analyses [20-23,27]

319 suggest this concern is also apropos to lipoproteins and adiposity GWAS.

320 
321 Important caveats to our analysis of phenotypes in family sets are: 1) heritability lacks the

322 specificity of directly measured genotypes even if it is a more inclusive measure of genetic

323 effects; and 2) Falconer's formula probably do not adequately address the true complexity of the

324 genetics and shared environment affecting adiponectin concentrations. These concerns can be

325 partly addressed by re-analyzing published studies that measured genetic variants directly from

326 the perspective of quantile-dependent expressivity. They include multiple examples where the

327 paper's original interpretation from the perspective of precision medicine or gene-environment

328 interactions might be more simply explained by a single underlying phenomenon: quantile-

329 dependent expressivity. Results are presented in their reported units.

330

331 Pharmacogenetics There is an important distinction between quantile-dependence and

332 pharmacogenetics. Pharmacogenetics attempts to use genetic markers that identify patients most

333 likely to benefit from specific treatments to individualize drug prescriptions. Quantile-dependent

334 expressivity postulates that drugs alter the phenotype (e.g., increase adiponectin concentrations),

335 which in turn alters the expressivity of genetic variants. More simply stated, genetic markers

336 merely track the increase in heritability with increasing adiponectin concentrations.

337

338 For example, rosiglitazone is a thiazolidinedione derivate that increases serum adiponectin

339 concentration by increasing adiponectin transcription [29]. Kang et al. [29] reported significantly

340 smaller increases in adiponectin concentrations in GG homozygotes of the at position 45

341 (rs2241766) of the ADIPOQ gene than carriers of the T allele after 166 T2DM's received 4

$342 \mathrm{mg} /$ day of rosiglitazone for 12 weeks $(\mathrm{P}<0.003$, Figure 5A histogram). Heterozygotes had an

343 intermediate response. Alternatively, from the perspective of quantile-dependent expressivity

344 (Figure 5A line graph) there were substantially greater differences in adiponectin concentrations

345 between genotypes at the end of treatment than at baseline (TT minus GG difference: 4.12 \pm 1.30

346 vs. $0.27 \pm 0.79 \mu \mathrm{g} / \mathrm{ml}$ ) in accordance with the significantly higher mean adiponectin

347 concentrations after treatment than before $(9.92 \pm 0.53$ vs. $5.30 \pm 0.37 \mu \mathrm{g} / \mathrm{ml}, \mathrm{P}<0.001)$.

348

349 Gene-environment interactions There are multiple reports of adiposity modulating genetic

350 influences on adiponectin concentrations, or equivalently, that these polymorphisms modulated

351 the effects of adiposity on adiponectin concentrations (Figure 5B-5D and 6A-6C histograms). 
352 These include the rs $266729(-11,377 \mathrm{C}>\mathrm{G})$ polymorphism located in the proximal promoter

353 region of the ADIPOQ gene and which functionally regulates adiponectin promoter activity and

354 adiponectin levels [56,57], rs1501299 $(+276 \mathrm{~T}>\mathrm{G})$ in ADIPOQ's intron 2, and the

355 aforementioned rs2241766 in ADIPOQ's exon 2.

356

357 De Luis et al. [31] reported significantly greater increases in adiponectin concentration in CC 358 homozygotes than G-carriers of the ADIPOQ rs266729 gene polymorphism when participants 359 switched from a basal diet to either a $27 \%$ low-fat hypocaloric (CC vs. G-carriers: $16.1 \pm 2.8$ vs. $3601.3 \pm 1.0 \mathrm{ng} / \mathrm{dL}, \mathrm{P}=0.03$ ) or a $38 \%$ high fat hypocaloric $\operatorname{diet}(10.6 \pm 2.0$ vs. $1.8 \pm 1.0 \mathrm{ng} / \mathrm{dL}, \mathrm{P}=0.01)$ 361 for three months (Figures 5B histogram, pooled across diets). Both diets produced significant 362 weight loss: $4.5 \pm 0.9 \mathrm{~kg}$ on the high-fat and $4.1 \pm 0.9 \mathrm{~kg}$ on the low-fat diet. Alternatively, on the 363 high-fat diet, the adiponectin difference between genotypes was greater after weight loss $364(8.3 \pm 0.8 \mathrm{ng} / \mathrm{dL})$ when the overall average concentration was higher $(16.9 \pm 0.4 \mathrm{ng} / \mathrm{dL})$ vis-à-vis 365 before weight loss $(-0.5 \pm 0.7 \mathrm{ng} / \mathrm{dL})$ when overall average concentration was lower $(9.8 \pm 0.3$ $366 \mathrm{ng} / \mathrm{dL}$ ). Similarly, on the low-fat diet there was a larger adiponectin difference between 367 genotypes after weight loss $(14.0 \pm 1.3 \mathrm{ng} / \mathrm{dL})$ at the higher average concentration $(21.5 \pm 0.8$ $\mathrm{ng} / \mathrm{dL})$ vis-à-vis before weight loss $(-1.8 \pm 1.1 \mathrm{ng} / \mathrm{dL})$ at the lower average concentration $(10.8 \pm 0.7 \mathrm{ng} / \mathrm{dL})$ [31], suggesting that quantile-dependent expressivity may have contributed to the genotype-specific increases (Figure 5B line graph for the pooled results).

372 From the same laboratory, Aller et al. [38] reported greater 9-month increases in adiponectin 373 concentrations in GG homozygotes of the rs1501299 gene than T-allele carriers when switching 374 from their basal diet to one of two severe hypocaloric diets: a standard version and a high-protein 375 low-carbohydrate version. Both diets increased adiponectin significantly in GG homozygotes 376 (standard: $10.9 \mathrm{ng} / \mathrm{ml}, \mathrm{P}<0.05$; high-protein: $10.1 \mathrm{ng} / \mathrm{ml}, \mathrm{P}<0.05$ ) but not in carriers of the $\mathrm{T}$ 377 allele (standard: $0.6 \mathrm{ng} / \mathrm{ml}$; high-protein: $2.6 \mathrm{ng} / \mathrm{ml}$ ). Their pooled results are presented in Figure 378 5C histogram. However, for both diets average adiponectin concentrations were higher after 9379 month weight loss (standard: $15.4 \pm 0.5 \mathrm{ng} / \mathrm{ml}$; high-protein: $16.3 \pm 0.4 \mathrm{ng} / \mathrm{ml}$ ) than at baseline 380 (standard: $10.3 \pm 0.5 \mathrm{ng} / \mathrm{ml}$; high-protein: $10.1 \pm 0.3 \mathrm{ng} / \mathrm{ml}$ ), and in accordance with quantile381 dependent expressivity, the difference between GG and T-allele carriers was greater for the 382 higher average concentrations after weight loss (standard: $11.5 \pm 1.0 \mathrm{ng} / \mathrm{ml}$; high-protein: $7.3 \pm 0.9$ 
$383 \mathrm{ng} / \mathrm{ml}$ ) than at the low average concentrations at baseline (standard: $1.2 \pm 0.9 \mathrm{ng} / \mathrm{ml}$; high-protein: $384-0.2 \pm 0.6 \mathrm{ng} / \mathrm{ml}$ ). The line graph of Figure 5C presents this quantile-dependent interpretation for 385 the pooled sample.

386

387 De Luis et al. [32] also reported that rs266729 CC homozygote had significantly greater 388 adiponectin increases than G-carriers when 149 morbidly obese patients lost an average of 41.9 $389 \mathrm{~kg}$ during the three years following biliopancreatic diversion surgery (Figure 5D histogram, $39033.2 \pm 0.4$ vs. $4.7 \pm 0.2 \mathrm{ng} / \mathrm{ml} ; \mathrm{P}=0.01$ ). From the perspective of quantile-dependent expressivity, 391 the genetic effect size between CC homozygotes and G-allele carriers increased as mean 392 adiponectin concentration increased from $17.0 \pm 0.4 \mathrm{ng} / \mathrm{ml}$ pre-surgery $(8.7 \pm 0.8 \mathrm{ng} / \mathrm{ml}$ difference 393 between genotypes), to $27.1 \pm 0.5 \mathrm{ng} / \mathrm{ml}$ one-year post surgery $(22.5 \pm 1.0 \mathrm{ng} / \mathrm{ml}$ genotype 394 difference), $31.8 \pm 0.4 \mathrm{ng} / \mathrm{ml}$ two-years post surgery ( $29.8 \pm 0.9 \mathrm{ng} / \mathrm{ml}$ genotype difference), and $39537.7 \pm 0.5 \mathrm{ng} / \mathrm{ml}$ three-years post surgery $(37.1 \pm 1.1 \mathrm{ng} / \mathrm{ml}$ genotype difference).

397 A third study by de Luis et al. [33] reported that rs266729 CC homozygotes had significantly 398 greater adiponectin increases than G-carriers (Figure 6A histogram, 10.4 $\pm 3.1 \mathrm{vs} .-1.3 \pm 1.0 \mathrm{ng} / \mathrm{ml}$, $399 \mathrm{P}=0.01$ ) when 83 obese patients lost an average of $3.5 \pm 0.6 \mathrm{~kg}$ after a 3 -month Mediterranean400 type hypocaloric diet. Again, from the perspective of quantile-dependent expressivity, the 401 genetic effect size between CC homozygoes and G-allele carriers increased as mean adiponectin 402 increased from the pre-diet $23.8 \pm 0.6 \mathrm{ng} / \mathrm{ml}$ average $(10.2 \pm 1.1 \mathrm{ng} / \mathrm{dL}$ genotype difference) to the $40328.5 \pm 0.4 \mathrm{ng} / \mathrm{ml}$ post-diet average $(21.9 \pm 0.9 \mathrm{ng} / \mathrm{ml}$ difference $)$.

404

405 Cross-sectionally, Divella et al. [35] reported that the difference in adiponectin concentration 406 between obese and normal weight colorectal cancer patients was greater in rs266729 CC 407 homozygotes than CG/GG genotypes ( $44.5 \pm 10.4$ vs. $32.3 \pm 10.1 \mathrm{ng} / \mathrm{ml}$, Figure $6 \mathrm{~B}$ histogram). 408 Consistent with quantile-dependent expressivity, the associated line graph shows that the 409 difference between genotypes increased as mean adiponectin concentrations increased from $41046.3 \pm 4.2 \mathrm{ng} / \mathrm{ml}$ in obese (genotype difference $22.1 \pm 8.9 \mathrm{ng} / \mathrm{ml}$ ), $51.8 \pm 5.5 \mathrm{ng} / \mathrm{ml}$ in overweight $411(30.6 \pm 16.3 \mathrm{ng} / \mathrm{ml}$ difference, not displayed), to $94.6 \pm 5.7 \mathrm{ng} / \mathrm{ml}$ in normal weight patients $412(34.3 \pm 11.5 \mathrm{ng} / \mathrm{ml}$ difference $)$. 
414 Garcia-Garcia et al. [36] concluded that adiponectin levels were modulated by the interaction

415 between BMI and ADIPOQ -11391G/A SNP on the basis of a significant adiponectin difference

416 between GA and GG genotypes in the $1^{\text {st }}(1.30 \pm 0.66 \mu \mathrm{g} / \mathrm{ml}, \mathrm{P}=0.03)$ but not $2^{\text {nd }}(0.2 \pm 0.29$

$417 \mu \mathrm{g} / \mathrm{mL})$ nor $3^{\text {rd }}$ BMI tertiles $(0.2 \pm 0.24 \mu \mathrm{g} / \mathrm{ml})$, consistent with quantile-dependent expressivity

418 given that mean adiponectin concentrations were significantly higher in the $1^{\text {st }}(4.20 \pm 0.28 \mu \mathrm{g} / \mathrm{ml})$

419 than the $2^{\text {nd }}(3.09 \pm 0.15)$ or $3^{\text {rd }}$ BMI tertiles $(2.30 \pm 0.12 \mu \mathrm{g} / \mathrm{ml})$.

420

421 Berthier et al. [37] reported that visceral adiposity modulated the effect of the rs2241766

$422 A D I P O Q$ gene polymorphism on adiponectin concentrations. Otherwise stated, Figure 6C

423 histogram (estimated from their figure 1) shows the effect of visceral fat was greater in carriers

424 of the G-allele than TT homozygotes. From the perspective of quantile-dependent expressivity,

425 the genetic effect size was greater in the less-viscerally obese than viscerally obese subjects $(6.0$

426 vs. $0.4 \mu \mathrm{g} / \mathrm{L})$ in accordance with their higher average adiponectin concentrations.

427

428 Sex-specific genetic effects Quantile-dependent expressivity, in conjunction with the higher

429 average adiponectin concentrations in women than men $(6.04 \pm 0.10 \mathrm{vs} .4 .08 \pm 0.10 \mu \mathrm{g} / \mathrm{ml})$, might

430 explain Riestra et al. [59] report that ADIPOQ variants rs6444174, rs16861205, rs1403697, and

431 rs7641507 were strongly associated with serum adiponectin concentration in women but not

432 men.

433

434 Postprandial lipemia The dependence of genetic effects on mean adiponectin concentrations has 435 also been demonstrated within individuals during their postprandial response. Carriers of the 436 45TT (rs2241766) and 276GT/TT (rs1501299) ADIPOQ haplotype have a higher T2DM and

437 cardiovascular disease risk than noncarriers. As derived from Musso et al's report [30], Figure 7

438 shows that the haplotype's blunted affects on the postprandial adiponectin concentrations

439 following an oral fat load were linearly related to the average adiponection concentrations at time $440 \mathrm{t}$ (linear regression, $4 \mathrm{df}, \mathrm{P}=0.0002)$.

441

442 Caveats and limitations None of the SNPs identified to date explain any more than a few 443 percent of adiponectin heritability, which means that the effects of any particular SNP is not

444 necessarily constrained by the results of Figure 1. Exceptions to Figure 1 include Hara et al. [60] 
445 report of significant adiponectin differences between $A D I P O Q$ rs1501299 genotypes for obese

446 Japanese whose mean concentrations were low, but not lean Japanese whose mean adiponectin

447 concentrations were higher; and Gupta et al. reported that the $A D I P O Q$ rs2241766

448 polymorphism significantly affected adiponectin in patients with nonalcoholic fatty liver disease

449 but not controls despite the lower mean concentration of the patients (4.8 vs. $7.2 \mu \mathrm{g} / \mathrm{ml})[61]$. We

450 also acknowledge that the simple estimates of $h^{2}$ from Falconer formula probably do not

451 adequately describe adiponectin inheritance [41], i.e., those derived from $\beta_{\mathrm{OP}}$ may include shared

452 environmental effects, and those derived from $\beta_{\mathrm{FS}}$ may include shared environment and

453 dominance effects and unmet restrictions on assortative mating. We note that the analyses were

454 based on total rather than the biologically more active high molecular weight adiponectin.

455 Finally, quantile-dependent expressivity represents an alternative interpretation to the gene-

456 environment and precision medicine interpretations presented by others, but our analyses do not

457 negate the original interpretation. Our analyses do not address the relationships of adiponectin to

458 disease risk factors or endpoints, and therefore cannot provide insight to adiponectin paradox

459 regarding all-cause and cardiovascular mortality [3].

460

461 In conclusion, heritability of adiponectin concentrations is quantile-dependent, which appears to

462 explain the stronger heritability in women in accordance with their higher concentrations, and is

463 consistent with the interactions of genes with thiazolidinedione, adiposity, and postprandial

464 changes reported by others. Prior reports of adiponectin heritability overlooked the effects of sex

465 on heritability because of their use parametric statistics requiring logarithmic transformations.

466 Genome-wide association studies of adiponectin also exclusively report on logarithmically

467 transformed concentrations. Should we have chosen to log-transform adiponectin concentrations,

468 the analyses would still have shown quantile-specific effects, but with heritability decreasing

469 with increasing concentrations (Supplementary Figure 1). We analyzed untransformed

470 adiponectin concentrations because quantile-regression is does not require normality, and no

471 biological rationale has been proposed for their logarithmic transformation. Parenthetically, the

472 significant interactions reported by Kang et al. [29], de Luis et al. [31-33], Divella et al. [35],

473 Aller et al [38], and Garcia-Garcia et al. [36] were all based on untransformed adiponectin

474 concentrations.

475 
476

477

478

479

480

481

482

483

484

485

486

Peer) reviewing PDF | (2020:06:50531:1:1:NEW 10 Sep 2020) 
1. Swarbrick MM, Havel PJ. Physiological, pharmacological, and nutritional regulation of 491

492 circulating adiponectin concentrations in humans. Metab Syndr Relat Disord.

493

494

2. Li S, Shin HJ, Ding EL, Van Dam RM. Adiponectin levels and risk of type 2 diabetes: a 495 systematic review and meta-analysis. JAMA 2009; 302:179-88.

496

497

3. Menzaghi C, Trischitta $\mathrm{V}$. The adiponectin paradox for all-Ccause and cardiovascular 498 mortality. Diabetes. 2018;67:12-22. doi:10.2337/dbi17-0016

499

500

4. Lindsay RS, Funahashi T, Krakoff J, Matsuzawa Y, Tanaka S, Kobes S, Bennett PH,

501 Tataranni PA, Knowler WC, Hanson RL. Genome-wide linkage analysis of serum

502 adiponectin in the Pima Indian population. Diabetes. 2003;52:2419-25. doi:

503 10.2337/diabetes.52.9.2419.

504

505

5. Liu PH, Jiang YD, Chen WJ, Chang CC, Lee TC, Sun HS, Chuang LM. Genetic and

506 environmental influences on adiponectin, leptin, and BMI among adolescents in

507 Taiwan: a multivariate twin/sibling analysis. Twin Res Hum Genet. 2008;11:495-504.

508 doi: 10.1375/twin.11.5.495.

509

510

6. Hicks C, Zhu X, Luke A, Kan D, Adeyemo A, Wu X, Cooper RS. A genome-wide scan of

511 loci linked to serum adiponectin in two populations of African descent. Obesity

512 (Silver Spring). 2007;15:1207-14. doi: 10.1038/oby.2007.142.

513

514 7. Comuzzie AG, Funahashi T, Sonnenberg G, Martin LJ, Jacob HJ, Black AE, Maas D, 515

516 Takahashi M, Kihara S, Tanaka S, Matsuzawa Y, Blangero J, Cohen D, Kissebah A. The genetic basis of plasma variation in adiponectin, a global endophenotype for obesity and the metabolic syndrome. J Clin Endocrinol Metab. 2001;86:4321-5. doi: 10.1210/jcem.86.9.7878. 
520 8. Vaughan LK, Wiener HW, Aslibekyan S, Allison DB, Havel PJ, Stanhope KL, O'Brien

521 DM, Hopkins SE, Lemas DJ, Boyer BB, Tiwari HK. Linkage and association analysis of 522 obesity traits reveals novel loci and interactions with dietary n-3 fatty acids in an 523 Alaska Native (Yup'ik) population. Metabolism. 2015;64:689-97. doi:

$524 \quad$ 10.1016/j.metabol.2015.02.008.

525

526 9. Chuang LM, Chiu YF, Sheu WH, Hung YJ, Ho LT, Grove J, Rodriguez B, Quertermous T, 527

528 Chen YD, Hsiung CA, Tai TY; Stanford Asia-Pacific Program of Hypertension and

529 Insulin Resistance Study Group. Biethnic comparisons of autosomal genomic scan for

530 loci linked to plasma adiponectin in populations of Chinese and Japanese origin. J Clin

531

532

533 Endocrinol Metab. 2004;89:5772-8. doi: 10.1210/jc.2004-0640.

\section{4}

535

10. Dosaev T, Prakash J, Livshits G. Contribution of body composition components and soft-tissue biochemical factors to genetic variation of body mass index (BMI) in an ethnically homogeneous population. Am J Hum Biol. 2014;26:760-7. doi:

536

11. Pollin TI, Tanner K, O'connell JR, Ott SH, Damcott CM, Shuldiner AR, McLenithan JC, 10.1002/ajhb.22583.

539 Mitchell BD. Linkage of plasma adiponectin levels to 3q27 explained by association with variation in the APM1 gene. Diabetes. 2005;54:268-274.

541

542 12. Henneman P, Aulchenko YS, Frants RR, Zorkoltseva IV, Zillikens MC, Frolich M, doi:10.2337/diabetes.54.1.268 Oostra BA, van Dijk KW, van Duijn CM. Genetic architecture of plasma adiponectin overlaps with the genetics of metabolic syndrome-related traits. Diabetes Care. 2010 Apr;33(4):908-13. doi: 10.2337/dc09-1385.

13. Menzaghi C, Salvemini L, Paroni G, De Bonis C, Mangiacotti D, Fini G, Doria A, Di Paola $\mathrm{R}$, Trischitta V. Circulating high molecular weight adiponectin isoform is heritable and shares a common genetic background with insulin resistance in nondiabetic 
550

551

552

553

554

555

556

557

558

559

560

561

562

563

564

565

566

567

568

569

570

571

572

573

574

575

576

577

578

White Caucasians from Italy: evidence from a family-based study. J Intern Med. 2010;267:287-94. doi: 10.1111/j.1365-2796.2009.02141.x.

14. Al-Daghri NM, Al-Attas OS, Alokail MS, Alkharfy KM, Yakout SM, Sabico SB, Gibson GC, Chrousos GP, Kumar S. Parent-offspring transmission of adipocytokine levels and their associations with metabolic traits. PLoS One. 2011;6:e18182. doi: 10.1371/journal.pone.0018182.

15. Guo X, Saad MF, Langefeld CD, Williams AH, Cui J, Taylor KD, Norris JM, Jinagouda S, Darwin CH, Mitchell BD, Bergman RN, Sutton B, Chen YD, Wagenknecht LE, Bowden DW, Rotter JI. Genome-wide linkage of plasma adiponectin reveals a major locus on chromosome 3q distinct from the adiponectin structural gene: the IRAS family study. Diabetes. 2006;55:1723-30. doi: 10.2337/db05-0428.

16. Ling H, Waterworth DM, Stirnadel HA et al. Genome-wide linkage and association analyses to identify genes influencing adiponectin levels: the GEMS study. Obesity (Silver Spring) 2009;17:737-44

17. Vasseur F, Helbecque N, Dina C, Lobbens S, Delannoy V, Gaget S, Boutin P, Vaxillaire M, Leprêtre F, Dupont S, Hara K, Clément K, Bihain B, Kadowaki T, Froguel P. Singlenucleotide polymorphism haplotypes in the both proximal promoter and exon 3 of the APM1 gene modulate adipocyte-secreted adiponectin hormone levels and contribute to the genetic risk for type 2 diabetes in French Caucasians. Hum Mol Genet. 2002;11:2607-14. doi: 10.1093/hmg/11.21.2607.

18. Cesari M, Narkiewicz K, De Toni R, Aldighieri E, Williams CJ, Rossi GP. Heritability of plasma adiponectin levels and body mass index in twins. J Clin Endocrinol Metab. 2007;92:3082-8. doi: 10.1210/jc.2007-0403. 
579 19. Butte NF, Comuzzie AG, Cai G, Cole SA, Mehta NR, Bacino CA. Genetic and

580 environmental factors influencing fasting serum adiponectin in Hispanic children. J

581 Clin Endocrinol Metab. 2005;90:4170-6. doi: 10.1210/jc.2004-2328.

582

583 20. Williams PT. Quantile-specific penetrance of genes affecting lipoproteins, adiposity $584 \quad$ and height. PLoS One. 2012;7:e28764.

585

586 21. Williams PT. Quantile-dependent heritability of computed tomography, dual-energy 587

588 $\mathrm{x}$-ray absorptiometry, anthropometric, and bioelectrical measures of adiposity. Int J

589

590

22. Williams PT. Quantile-specific heritability of high-density lipoproteins with

591 implications for precision medicine. J Clin Lipid 2020 (in press)

592

593 23. Williams PT. Gene-environment interactions due to quantile-specific heritability of

594 triglyceride and VLDL concentrations. Scientic Reports 2020;10:4486.

595

596

24. Williams PT. Spirometric traits show quantile-dependent heritability, which may

597 contribute to their gene-environment interactions with smoking and pollution. PeerJ.

598 2020;8:e9145.

599

600

25. Williams PT. Quantile-specific heritability may account for gene-environment

601 interactions involving coffee consumption. Behav Genet. 2020 50:119-26.

602

603

26. Williams PT. Quantile-specific heritability of intakes of alcohol but not other

604 macronutrients. Behav Genet. 2020 (in press)

605

606

27. Williams PT. Quantile-dependent expressivity of postprandial lipemia. PLoS One.

607 2020;15:e0229495.

608 
609 28. Berra M, Armillotta F, D’Emidio L et al. Testosterone decreases adiponectin levels in 610 female to male transsexuals. Asian J Androl 2006;8:725-729.

611

612 29. Kang ES, Park SY, Kim HJ, Ahn CW, Nam M, Cha BS, Lim SK, Kim KR, Lee HC. The 613 influence of adiponectin gene polymorphism on the rosiglitazone response in

614 patients with type 2 diabetes. Diabetes Care. 2005;28(5):1139-44. doi:

615 10.2337/diacare.28.5.1139.

616

617

30. Musso G, Gambino R, De Michieli F, Durazzo M, Pagano G, Cassader M. Adiponectin 618 gene polymorphisms modulate acute adiponectin response to dietary fat: Possible

619 pathogenetic role in NASH. Hepatology. 2008;47:1167-77. doi: 10.1002/hep.22142.

620

621

31. de Luis DA, Primo D, Izaola O, Aller R. Adiponectin Gene Variant rs266729 Interacts 622

623 with Different Macronutrient Distribution of Two Different Hypocaloric Diets.

624

625

626 Lifestyle Genom. 2020;13:20-27.

627

32. de Luis DA, Calvo SG, Pacheco D, Ovalle HF, Aller R. Adiponectin gene variant rs266729: Relation to lipid profile changes and circulating adiponectin after

628

629

33. de Luis DA, Primo D, Izaola O, Gomez Hoyos E, Lopez Gomez JJ, Ortola A, et al. Role of 630

631 the variant in adiponectin gene rs266729 on weight loss and cardiovascular risk

632 factors after a hypocaloric diet with the Mediterranean pattern. Nutrition.

633

634 34. Corbi G, Polito R, Monaco ML, Cacciatore F, Scioli M, Ferrara N, Daniele A,Nigro E. 635 Adiponectin Expression and Genotypes in Italian People with Severe Obesity

637 Undergone a Hypocaloric Diet and Physical Exercise Program. Nutrients. 2019;11. 638 pii: E2195. doi: 10.3390/nu11092195. 
639 35. Divella R, Daniele A, Mazzocca A, Abbate I, Casamassima P, Caliandro C, Ruggeri E, 640 Naglieri E, Sabbà C, De Luca R. ADIPOQ rs266729 G/C gene polymorphism and 641 plasmatic adipocytokines connect metabolic syndrome to colorectal cancer. J Cancer. 642 2017;8:1000-1008. doi: 10.7150/jca.17515.

643

644 36. Garcia-Garcia MR, Morales-Lanuza MA, Campos-Perez WY, Ruiz-Madrigal B, 645 Maldonado-Gonzalez M, Vizmanos B, Hernandez-Cañaveral I, Yañez-Sanchez I, 646 Roman S, Panduro A, Martinez-Lopez E. Effect of the ADIPOQ Gene -11391G/A 647 Polymorphism Is Modulated by Lifestyle Factors in Mexican Subjects. J Nutrigenet 648 Nutrigenomics. 2014;7:212-24. doi: 10.1159/000371801.

649

650

37. Berthier MT, Houde A, Côté M, et al. Impact of adiponectin gene polymorphisms on 651 plasma lipoprotein and adiponectin concentrations of viscerally obese men. J Lipid 652 Res. 2005;46:237-244. doi:10.1194/jlr.M400135-JLR200

653

654

655

656

657

38. Aller R, Izaola O, Primo D, de Luis DA. The effect of single-nucleotide polymorphisms at the ADIPOQ gene locus rs1501299 on metabolic parameters after 9 mo of a highprotein/low-carbohydrate versus a standard hypocaloric diet. Nutrition. 2019

658

659

660 Sep;65:44-49. doi: 10.1016/j.nut.2019.02.012.

39. Koenker R, Hallock KF. Quantile regression. J Economic Perspectives. 2001;15:143661 662 663

40. Gould WW. Quantile regression with bootstrapped standard errors. Stata Technical 664

41. Falconer DS, Mackay TFC. Introduction to Quantitative Genetics (fourth ed.) Pearson Education Limited, Harlow, Essex, UK 1996 ISBN-13: 978-0582243026

667

668 669

42. Dawber TR, Meadors GF, Moore FEJ. Epidemiological approaches to heart disease: the Framingham Study. Am J Public Health 1951;41:279-86. 
670

671 43. Kannel WB, Feinleib M, McNamara PM, Garrison RJ, Castelli WP. An investigation of

672 coronary heart disease in families. The Framingham offspring study. Am J Epidemiol.

$673 \quad 1979 ; 110: 281-90$.

674

675 44. Splansky GL, Corey D, Yang Q, Atwood LD, Cupples LA, Benjamin EJ, D'Agostino RB Sr, 676 Fox CS, Larson MG, Murabito JM, O'Donnell CJ, Vasan RS, Wolf PA, Levy D. The Third

677 Generation Cohort of the National Heart, Lung, and Blood Institute's Framingham

678

679 Heart Study: design, recruitment, and initial examination. Am J Epidemiol.

680

45. Dastani Z, Hivert MF, Timpson N, Perry JR, Yuan X, Scott RA, Henneman P, Heid IM, 682 Kizer JR, Lyytikainen LP, et al: Novel loci for adiponectin levels and their influence on 683 684 type 2 diabetes and metabolic traits: a multi- ethnic meta-analysis of 45,891

685 686 687 individuals. PLoS Genet 2012, 8:e1002607.

46. Heid IM, Henneman P, Hicks A, Coassin S, Winkler T, et al. Clear detection of ADIPOQ locus as the major gene for plasma adiponectin: results of genome-wide association 688 analyses including 4659 European individuals. Atherosclerosis 2010;208: 412-420.

689

690

47. Zachariah JP, Quiroz R, Nelson KP, Teng Z, Keaney JF, Sullivan LM, Vasan RS.

691

692 Prospective relation of circulating adipokines to incident metabolic syndrome: the

693 Framingham Heart Study. J Am Heart Assoc. 2017;6:e004974. DOI: 10.

694 695

48. Karlin S, Cameron EC, Williams PT. Sibling and parent-offspring correlation 696 estimation with variable family size. Proc Natl Acad Sci U S A. 1981;78:2664-8.

697

698 1161/JAHA.116.004974.

699

49. Winer BJ, Brown DR, Michels KM. 1991 Statistical principles in experimental design. Third edition. McGraw-Hill New York. 
701 50. Wilk MB, Gnanadesikan R. Probability plotting methods for the analysis of data",

$702 \quad$ Biometrika 1968;55:1-17.

703

704 51. NIH National Heart Lung, and Blood Institute Biologic Specimen and Data Repository

705

706 Information Coordinating Center https://biolincc.nhlbi.nih.gov/home/ • accessed June

707

708

52. dbGaP genotypes and phenotypes. Framingham cohort. dbGaP Study Accession:

709 phs000007.v30.p11 https://www.ncbi.nlm.nih.gov/projects/gap/cgi-

710 bin/study.cgi?study_id=phs000007.v30.p11 (Accessed June29, 2020).

711

712

53. Richards JB, Waterworth D, O’Rahilly S, Hivert MF, Loos RJ, et al. A genome-wide 713 association study reveals variants in ARL15 that influence adiponectin levels. PLoS

714 Genet 2009;5:e1000768. doi:10.1371/journal.pgen.1000768.

715

716

54. Jee SH, Sull JW, Lee JE, Shin C, Park J, et al. (2010) Adiponectin concentrations: a genome-wide association study. Am J Hum Genet 87: 545-552.

718

55. Ling H, Waterworth DM, Stirnadel HA, Pollin TI, Barter PJ, et al. (2009) Genome-wide

720

721

722 Linkage and Association Analyses to Identify Genes Influencing Adiponectin Levels: The GEMS Study. Obesity (Silver Spring). 2009;17:737-44. doi:

723

724 56. Gu HF. Biomarkers of adiponectin: plasma protein variation and genomic DNA

725 polymorphisms. Biomark Insights. 2009 Oct;4: 123-33.

726

727 57. Bouatia-Naji N, Meyre D, Lobbens S, Séron K, Fumeron F, Balkau B, et al.

728

729 ACDC/adiponectin polymorphisms are associated with severe childhood and adult obesity. Diabetes. 2006;55:545-50.

730 
731 58. Peters KE, Beilby J, Cadby G, et al. A comprehensive investigation of variants in genes

732

733

734

735

736

737

738

739

740

741

742

743

744

745

746

747

748

749

750 encoding adiponectin (ADIPOQ) and its receptors (ADIPOR1/R2), and their association with serum adiponectin, type 2 diabetes, insulin resistance and the metabolic syndrome. BMC Med Genet. 2013;14:15. doi:10.1186/1471-2350-14-15

59. Riestra P, Gebreab SY, Xu R, Khan RJ, Bidulescu A, Correa A, Tekola-Ayele F,Davis SK. Gender-specific associations between ADIPOQ gene polymorphisms andadiponectin levels and obesity in the Jackson Heart Study cohort. BMC Med Genet. 2015;16:65. doi: 10.1186/s12881-015-0214-X.

60. Hara K, Boutin P, Mori Y, Tobe K, Dina C, Yasuda K, Yamauchi T, Otabe S, Okada T, Eto K, Kadowaki H, Hagura R, Akanuma Y, Yazaki Y, Nagai R, Taniyama M, Matsubara K, Yoda M, Nakano Y, Tomita M, Kimura S, Ito C, Froguel P, Kadowaki T. Genetic variation in the gene encoding adiponectin is associated with an increased risk of type 2 diabetes in the Japanese population. Diabetes. 2002;51:536-40. doi: 10.2337/diabetes.51.2.536.

61. Gupta AC, Misra R, Sakhuja P, Singh Y, Basir SF, Sarin SK. Association of adiponectin gene functional polymorphisms $(-11377 \mathrm{C} / \mathrm{G}$ and $+45 \mathrm{~T} / \mathrm{G})$ with nonalcoholic fatty liver disease. Gene. 2012;496:63-7. doi: 10.1016/j.gene.2011.12.023. 
752

753 Figure 1. A) Offspring-parent regression slopes $\left(\beta_{\mathrm{OP}}\right)$ for selected quantiles of the offspring's 754 adiponectin concentrations from 4182 offspring-parent pairs, with corresponding estimates of 755 heritability $\left(h^{2}=2 \beta_{\mathrm{OP}} /\left(1+\mathrm{r}_{\text {spouse }}\right)\right.$, where the correlation between spouses was $\left.\mathrm{r}_{\text {spouse }}=0.04\right)$. The 756 slopes became progressively greater (i.e., steeper) with increasing quantiles of the adiponectin 757 distribution. B) The selected quantile-specific regression slopes were included with those of 758 other quantiles to create the quantile-specific heritability function in the lower panel.

759 Significance of the linear, quadratic and cubic trends and the $95 \%$ confidence intervals (shaded 760 region) determined by 1000 bootstrap samples. C) Quantile-specific full-sib regression slopes

$761\left(\beta_{\mathrm{FS}}\right)$ from 4587 siblings in 1662 sibships, with corresponding estimates of heritability as

762 estimated by $h^{2}=\left\{\left(8 \mathrm{r}_{\text {spouse }} \beta_{\mathrm{FS}}+1\right)^{0.5}-1\right\} /\left(2 \mathrm{r}_{\text {spouse }}\right) .95 \%$ confidence intervals (shaded region)

763 determined by 1000 bootstrap samples.

764

765 Figure 2. Distribution of fasting adiponectin concentrations in males and females.

766

767 Figure 3. A) Offspring-parent regression slopes $\left(\beta_{\mathrm{OP}}\right)$ in male and female offspring separately 768 from age- and sex-adjusted parent-son and parent-daughter pairs, showing their significant 769 difference when the slopes are compared at their corresponding percentiles (the sons' vs. the 770 daughters' $\beta_{\mathrm{OP}}$ compared at the $5^{\text {th }}$ percentile of separate distributions, the $6^{\text {th }}$ percentile of their 771 separate distributions, $\ldots, 95^{\text {th }}$ percentile of their separate distributions). Shaded area designates $772 \pm$ SE; B) Offspring-parent regression slopes $\left(\beta_{\mathrm{OP}}\right)$ in male and female offspring showing the 773 significant difference is eliminated when compared at their corresponding adiponectin 774 concentrations (the sons' vs. the daughters' $\beta_{\mathrm{OP}}$ translated using quantile-quantile (Q-Q) plots to 775 the adiponectin concentrations at the $5^{\text {th }}$ percentile of their combined distribution, the $6^{\text {th }}$ 776 percentile of their combined distribution, ..., 95 $5^{\text {th }}$ percentile of their combined distribution).

777 Shaded area designates \pm SE. C) Offspring-parent regression slopes for sons and daughters 778 combined without adjustment for sex, showing the unadjusted analysis provides a simpler 779 description of the quantile increase based solely on the percentiles of their unadjusted 780 adiponectin concentrations. Note that the separate curves for sons' and daughters' fall fully 781 within the $95 \%$ confidence interval (shaded area) for their combined sex-unadjusted analysis. 
783 Figure 4. A) Analyses showing that the full sib regression slopes $\left(\beta_{\mathrm{FS}}\right)$ was greater in female than

784 male siblings when matched by their corresponding percentiles, B) but not when matched by

785 their corresponding adiponectin concentrations, and C) that a simpler graph of their combined

786 male and female sibs, unadjusted for sex, includes their separate curves within its 95\%

787 confidence interval. See legend to Figure 3 for details. *exceptions were $\mathrm{P}=0.05$ at the $39^{\text {th }}$,

$788 \mathrm{P}=0.04$ at the $40^{\text {th }}$, and $\mathrm{P}=0.03$ at the $42^{\text {nd }}$ percentiles.

789

790 Figure 5. Precision medicine perspective of $A D I P O Q$ genotype-specific adiponectin differences

791 (histogram inserts) vs. quantile-dependent expressivity perspective (line graphs showing larger

792 genetic effect size when average adiponectin concentrations were high) for: A) Kang et al.'s

7932005 report [29] on the effect of 12-weeks $4 \mathrm{mg}$ /day of rosiglitazone treatment in $25 \mathrm{GG}$

794 rs2241766 homozygotes and 86 T-allele carriers with T2DM; B) de Luis et al.'s 2020 report [31]

795 on the pooled effect of switching from a basal to a 27\%- or 38\%-fat hypocaloric diet in 169

796 rs266729 CC homozygotes and 114 G-allele carriers; C) Aller et al.'s 2019 report [38] on the

797 pooled effect of switching from a basal to a standard or high-protein extreme hypocaloric diet in

798122 rs1501299 GG homozygotes than 147 T-allele carriers; D) de Luis et al's 2018 report [32]

799 on the effect of $41.9 \mathrm{~kg}$ weight loss from biliopancreatic diversion surgery in $84 \mathrm{rs} 266729 \mathrm{CC}$

800 homozygote and 65 G-allele carriers who were morbidly obesity. The histograms and line graphs

801 were derived from the mean concentrations presented in the original manuscripts.

802

803 Figure 6. Precision medicine perspective of $A D I P O Q$ genotype-specific adiponectin differences

804 (histogram inserts) vs. quantile-dependent expressivity perspective (line graph showing larger

805 genetic effect size when average adiponectin concentrations were high) for: A) de Luis et al.

8062019 report [33] on a 3-month Mediterranean-type hypocaloric diet in 48 rs266729 CC

807 homozygotes and 45 G-allele carriers; B) Divella et al. 2017 report [35] on the cross-sectional

808 difference between being obese and nonobese in 30 rs266729 CC homozygotes and 73 G-allele

809 carriers with colon cancer; and C) Berthier et al. [37] 2005 report of the cross-sectional

810 difference between high and low visceral adiposity (computed tomography $\geq 130 \mathrm{vs} .<130 \mathrm{~cm}^{2}$ )

811 in 26 rs2241766 TT-homozygotes vs. 117 male G-allele carriers. The histograms and line graphs

812 were derived from the mean concentrations presented in the original manuscripts.

813 
814 Figure 7. A) Re-rendering of Musso et al.'s 2008 published adiponectin response to an oral fat 815 tolerance test by 45TT (rs2241766) and 276GT/TT (rs1501299) ADIPOQ haplotypes [30]; B) 816 regression plot showing the genotypes difference (dependent variable) increased linearly with 817 increasing adiponectin concentrations (independent variable). The genotype-specific mean 818 concentrations were extracted from their figure 1C using the Microsoft PowerPoint formatting 819 palette.

820 
Table $\mathbf{1}$ (on next page)

Sample characteristics 
1

\begin{tabular}{|c|c|c|c|c|}
\hline & \multicolumn{2}{|c|}{ Males } & \multicolumn{2}{|c|}{ Females } \\
\hline & $\begin{array}{c}\text { Offspring } \\
\text { Cohort }\end{array}$ & $\begin{array}{c}\text { Third } \\
\text { generation } \\
\text { cohort }\end{array}$ & $\begin{array}{c}\text { Offspring } \\
\text { Cohort }\end{array}$ & $\begin{array}{c}\text { Third } \\
\text { generation } \\
\text { cohort }\end{array}$ \\
\hline Age, years & $61.21(9.63)$ & $40.44(8.62)$ & $60.93(9.41)$ & $39.91(8.73)$ \\
\hline BMI, $\mathrm{kg} / \mathrm{m}^{2}$ & $28.62(4.62)$ & $27.99(4.67)$ & $27.43(5.80)$ & $26.03(6.11)$ \\
\hline Adiponectin, $\mu \mathrm{g} / \mathrm{mL}$ & $7.45(6.63)$ & $6.09(3.82)$ & $12.59(6.71)$ & $10.97(5.77)$ \\
\hline
\end{tabular}

2

3 


\section{Figure 1}

Offspring-parent and full-sib quantile regression slopes

A) Offspring-parent regression slopes $\left(\beta_{\mathrm{OP}}\right)$ for selected quantiles of the offspring's adiponectin concentrations from 4182 offspring-parent pairs, with corresponding estimates of heritability $\left(h^{2}=2 \beta_{\mathrm{oP}} /\left(1+r_{\text {spouse }}\right)\right.$, where the correlation between spouses was $\left.r_{\text {spouse }}=0.04\right)$. The slopes became progressively greater (i.e., steeper) with increasing quantiles of the adiponectin distribution. B) The selected quantile-specific regression slopes were included with those of other quantiles to create the quantile-specific heritability function in the lower panel. Significance of the linear, quadratic and cubic trends and the $95 \%$ confidence intervals (shaded region) determined by 1000 bootstrap samples. C) Quantile-specific full-sib regression slopes $\left(b_{\mathrm{FS}}\right)$ from 4587 siblings in 1662 sibships, with corresponding estimates of

heritability as estimated by $h^{2}=\left\{\left(8 r_{\text {spouse }} \beta_{\mathrm{FS}}+1\right)^{0.5}-1\right\} /\left(2 \mathrm{r}_{\text {spouse }}\right) .95 \%$ confidence intervals (shaded region) determined by 1000 bootstrap samples. 

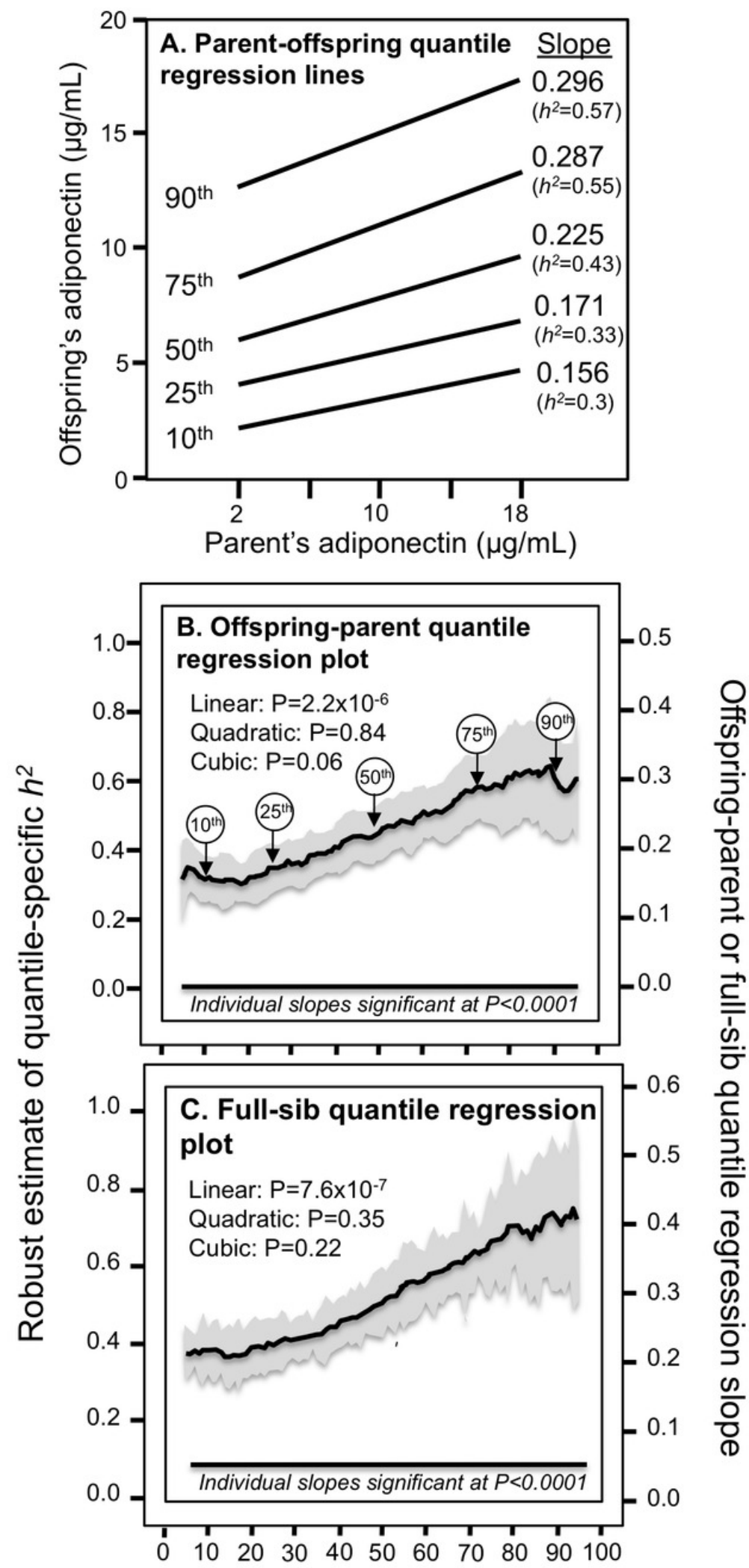

Percentiles of the offspring's or full sibs' adiponectin distribution 
Figure 2

Distribution of fasting adiponectin concentrations in males and females 


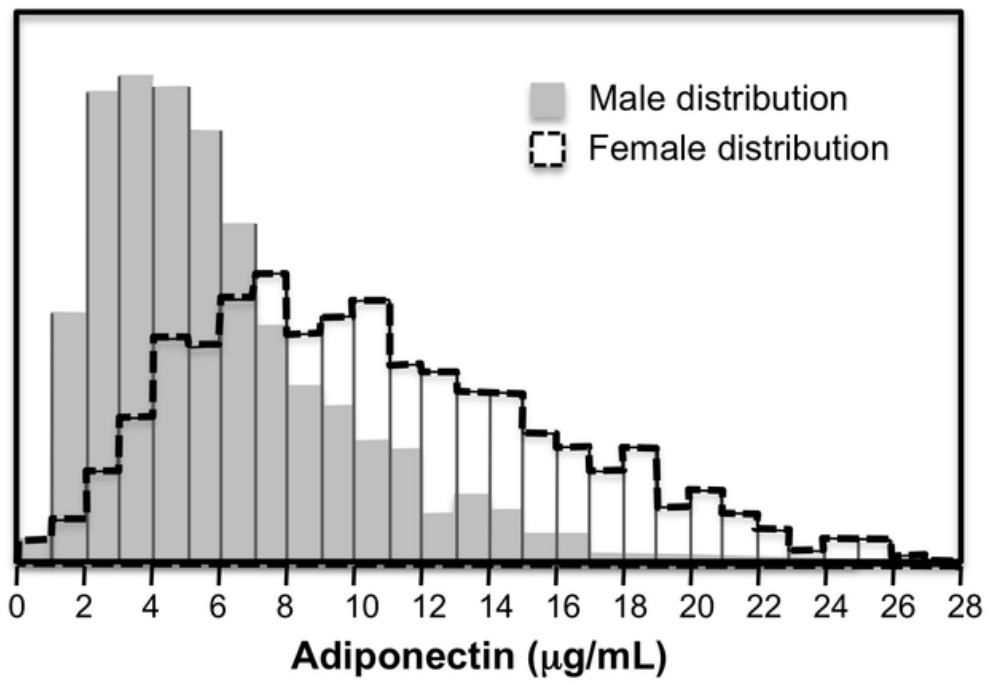




\section{Figure 3}

Offspring-parent quantile regression slopes ( $\beta_{\mathrm{op}}$ ) in male and female offspring separately.

A) Offspring-parent regression slopes $\left(\beta_{\text {op }}\right)$ in male and female offspring separately from ageand sex-adjusted parent-son and parent-daughter pairs, showing their significant difference when the slopes are compared at their corresponding percentiles (the sons' vs. the daughters' $\beta_{O P}$ compared at the $5^{\text {th }}$ percentile of separate distributions, the $6^{\text {th }}$ percentile of their separate distributions, $\ldots, 95^{\text {th }}$ percentile of their separate distributions). Shaded area designates $\pm \mathrm{SE}$; B) Offspring-parent regression slopes $\left(\beta_{\mathrm{op}}\right)$ in male and female offspring showing the significant difference is eliminated when compared th their corresponding adiponectin concentrations (the sons' vs. the daughters' $\beta_{\text {op }}$ translated using quantilequantile (Q-Q) plots to the adiponectin concentrations at the $5^{\text {th }}$ percentile of their combined distribution, the $6^{\text {th }}$ percentile of their combined distribution, $\ldots, 95^{\text {th }}$ percentile of their combined distribution). Shaded area designates \pm SE. C) Offspring-parent regression slopes for sons and daughters combined without adjustment for sex, showing the unadjusted analysis provides a simpler description of the quantile increase based solely on the percentiles of their unadjusted adiponectin concentrations. Note that the separate curves for sons' and daughters' fall fully within the $95 \%$ confidence interval (shaded area) for their combined sex-unadjusted analysis. 


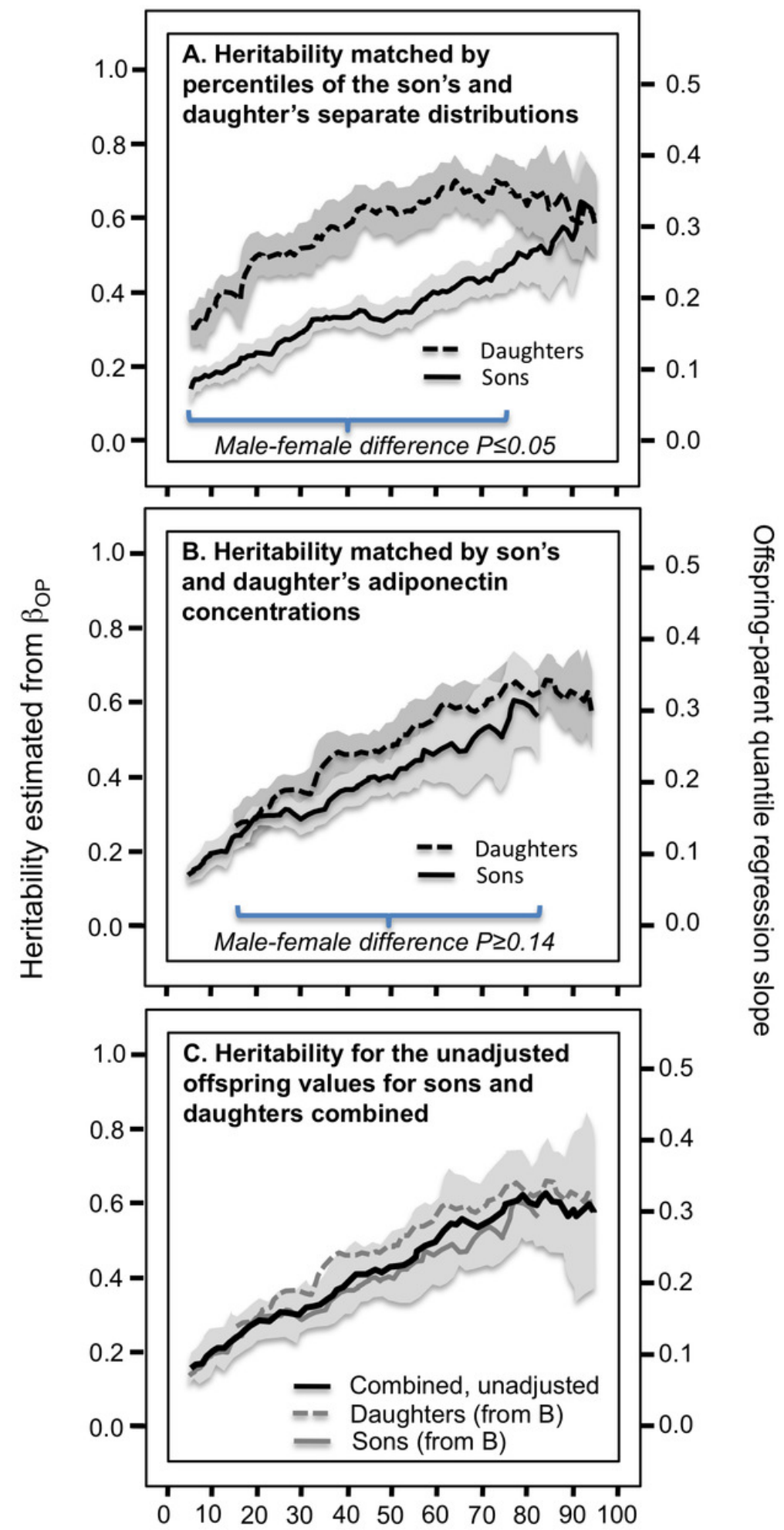

Percentiles of the offspring's distribution 


\section{Figure 4}

Full-sib quantile regression slopes $\left(\beta_{\mathrm{FS}}\right)$ in male and female offspring separately
A) Analyses showing that the full sib regression slopes $\left(\beta_{\mathrm{FS}}\right)$ was greater in female than male siblings when matched by their corresponding percentiles, B) but not when matched by their corresponding adiponectin concentrations, and C) that a simpler graph of their combined male and female sibs, unadjusted for sex, includes their separate curves within its $95 \%$ confidence interval. See legend to Figure 3 for details. *exceptions were $P=0.05$ at the $39^{\text {th }}$, $\mathrm{P}=0.04$ at the $40^{\text {th }}$, and $\mathrm{P}=0.03$ at the $42^{\text {nd }}$ percentiles. 

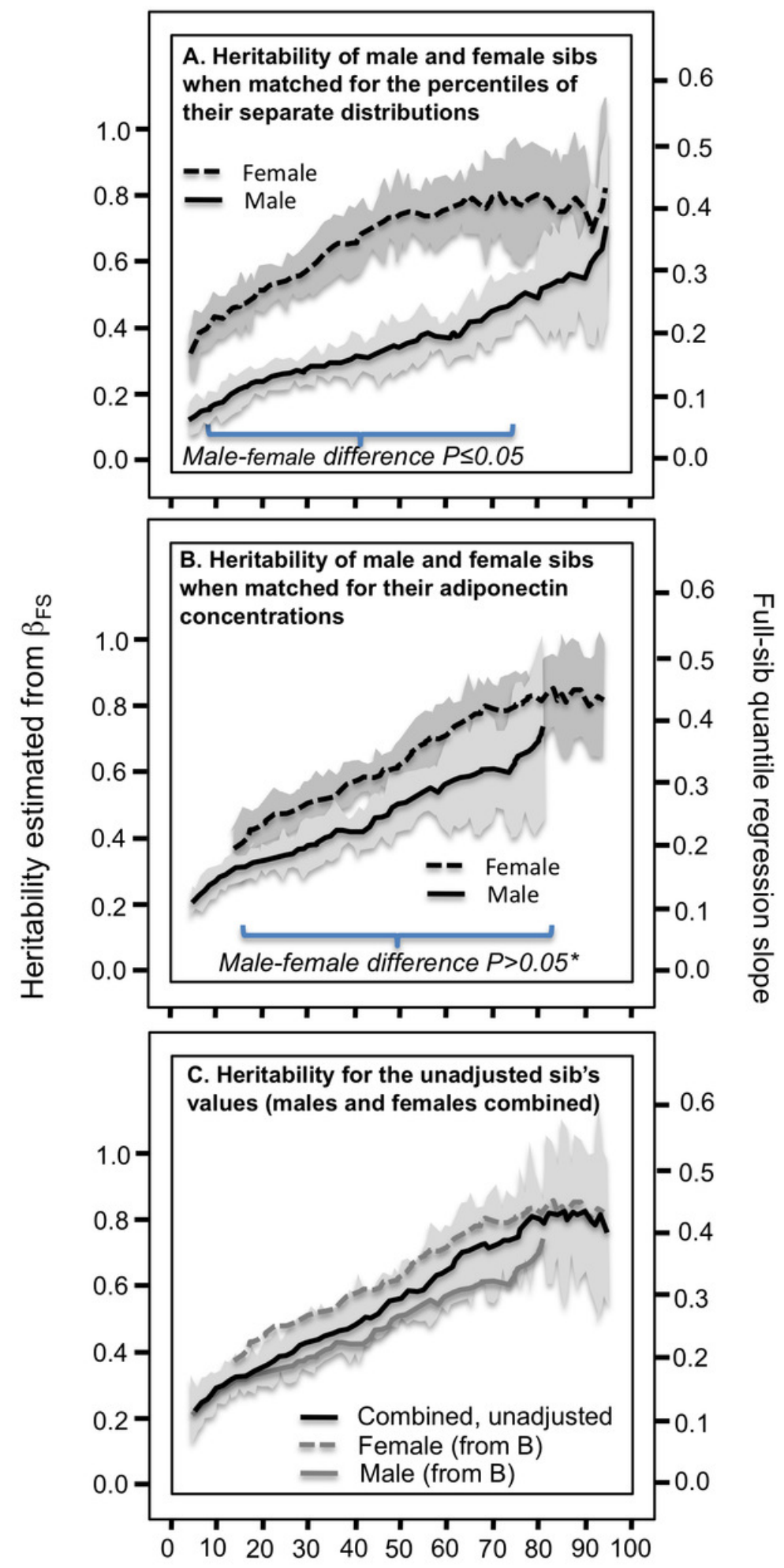

Percentiles of the offspring's distribution 


\section{Figure 5}

Precision medicine perspective of $A D I P O Q$ genotype-specific adiponectin differences (histogram inserts) vs. quantile-dependent expressivity perspective (line graphs)

Precision medicine perspective of $A D I P O Q$ genotype-specific adiponectin differences (histogram inserts) vs. quantile-dependent expressivity perspective (line graphs showing larger genetic effect size when average adiponectin concentrations were high) for: A) Kang et al.'s 2005 report [29] on the effect of 12-weeks $4 \mathrm{mg} /$ day of rosiglitazone treatment in 25 GG rs2241766 homozygotes and 86 T-allele carriers with T2DM; B) de Luis et al.'s 2020 report [31] on the pooled effect of switching from a basal to a $27 \%$ - or $38 \%$-fat hypocaloric diet in 169 rs266729 CC homozygotes and 114 G-allele carriers; C) Aller et al.'s 2019 report [38] on the pooled effect of switching from a basal to a standard or high-protein extreme hypocaloric diet in 122 rs1501299 GG homozygotes than 147 T-allele carriers; D) de Luis et al's 2018 report [32] on the effect of $41.9 \mathrm{~kg}$ weight loss from biliopancreatic diversion surgery in 84 rs 266729 CC homozygote and 65 G-allele carriers who were morbidly obesity. The histograms and line graphs were derived from the mean concentrations presented in the original manuscripts. 

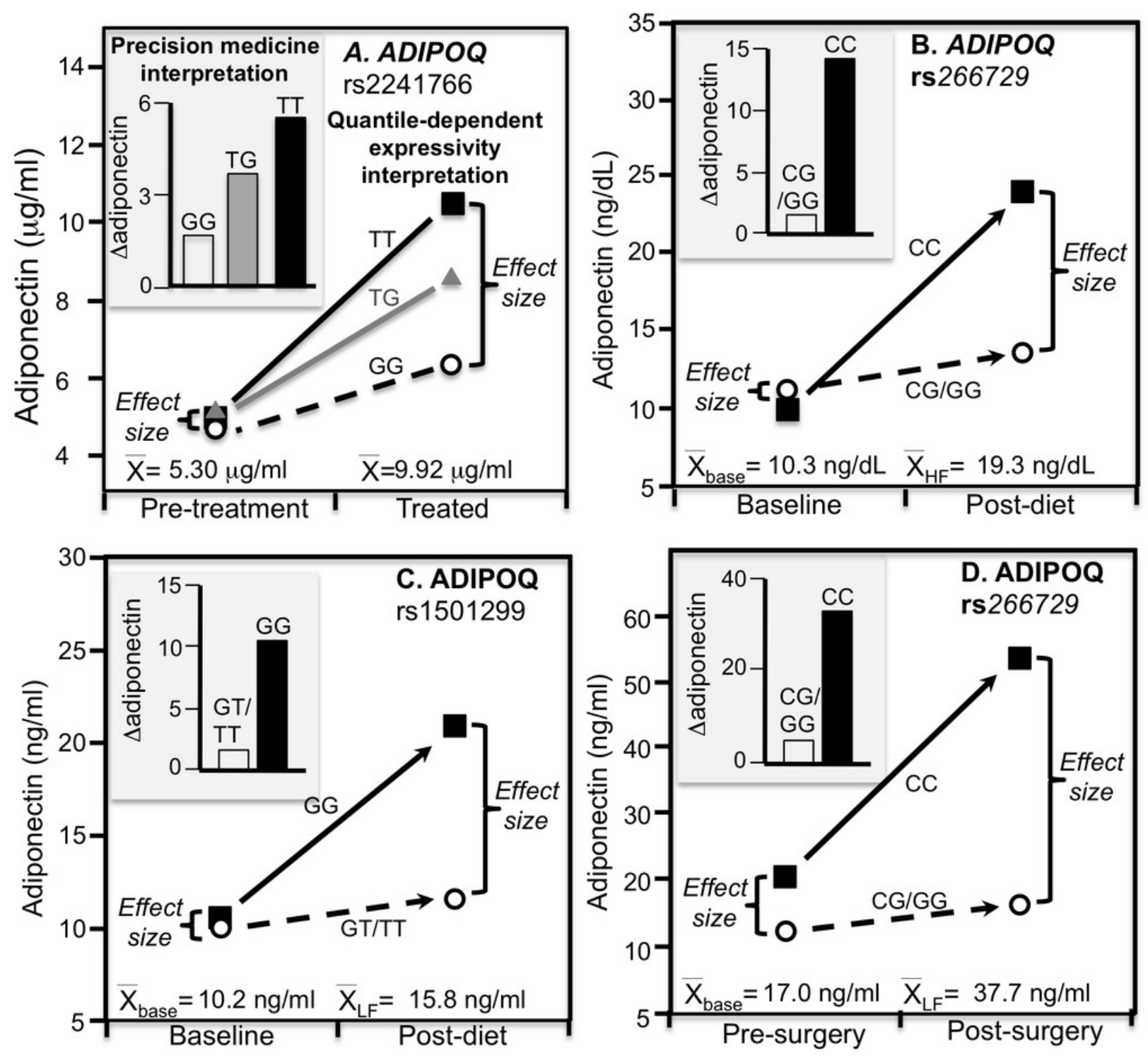


\section{Figure 6}

Precision medicine perspective of $A D I P O Q$ genotype-specific adiponectin differences (histogram inserts) vs. quantile-dependent expressivity perspective (line graphs).

Precision medicine perspective of $A D I P O Q$ genotype-specific adiponectin differences (histogram inserts) vs. quantile-dependent expressivity perspective (line graph showing larger genetic effect size when average adiponectin concentrations were high) for: A) de Luis et al. 2019 report [33] on a 3-month Mediterranean-type hypocaloric diet in 48 rs266729 CC homozygotes and 45 G-allele carriers; B) Divella et al. 2017 report [35] on the cross-sectional difference between being obese and nonobese in 30 rs 266729 CC homozygotes and 73 Gallele carriers with colon cancer; and C) Berthier et al. [37] 2005 report of the cross-sectional difference between high and low visceral adiposity (computed tomography $\geq 130$ vs. $<130$ $\mathrm{cm}^{2}$ ) in 26 rs2241766 TT-homozygotes vs. 117 male G-allele carriers. The histograms and line graphs were derived from the mean concentrations presented in the original manuscripts 

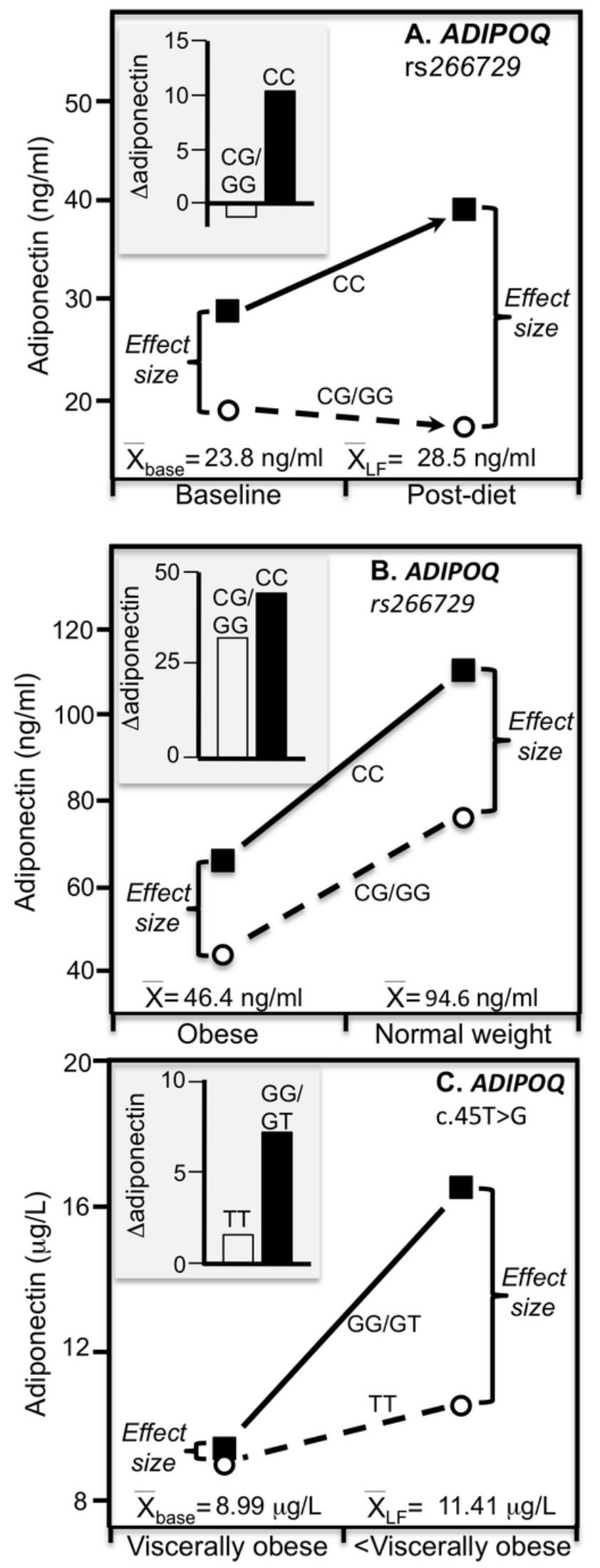


\section{Figure 7}

Adiponectin response to an oral fat tolerance test by $45 \mathrm{TT}$ ( $\mathrm{rs} 2241766$ ) and 276GT/TT (rs1501299) ADIPOQ haplotypes
A) Re-rendering of Musso et al.'s 2008 published adiponectin response to an oral fat tolerance test by 45TT (rs2241766) and 276GT/TT (rs1501299) ADIPOQ haplotypes [30]; B) regression plot showing the genotypes difference (dependent variable) increased linearly with increasing adiponectin concentrations (independent variable). The genotype-specific mean concentrations were extracted from their figure $1 \mathrm{C}$ using the Microsoft PowerPoint formatting palette. 

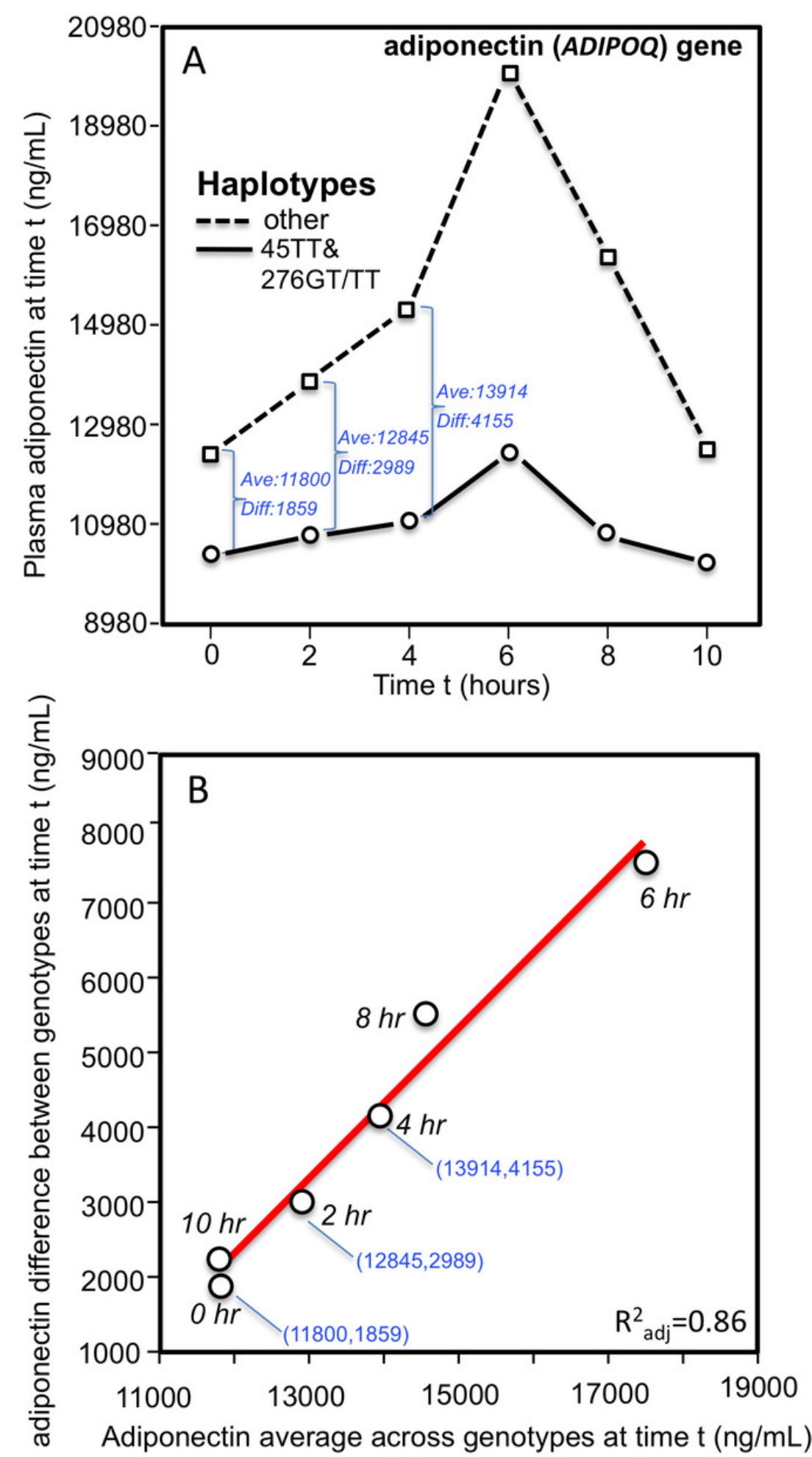